\title{
In Memoriam Julio Ruiz Berrio
}

Este es sólo uno más de los múltiples testimonios con los que, tras su fallecimiento en el pasado mes de octubre, han querido expresar su pesar muchos de sus amigos, colegas y discípulos. Tengan estas palabras el valor que tengan (y probablemente lo tengan especialmente para mí, que lo rememoro ahora), sumo el mío a ese pésame y reconocimiento colectivo, haciendo públicos algunos de mis recuerdos sobre la estrecha relación intelectual y personal que nos fue dado compartir y que se prolongó durante varias décadas.

Decano profesor de historia de la educación y de educación comparada en las universidades de Madrid y Oviedo; exhaustivo investigador, capaz de mimetizarse en archivos, bibliotecas, museos, hemerotecas y colecciones varias, a los que dedicó miles de horas de su vida; creador e impulsor -con una capacidad casi mágica para ello- del societarismo profesional; artífice d e b uena $p$ arte $\mathrm{d}$ el $\mathrm{m}$ arco i nstitucional d e e sa v ida societaria..., tales son algunas de las dimensiones que caracterizan indeleblemente su vida profesional, acerca de las cuales el conjunto del gremio de historiadores e historiadoras de la educación (nacionales e internacionales) posee experiencias directas. A través de ellas reconocimos el capital más genuino de Julio: su enorme capacidad para sembrar, para acoger, para estimular, exigir, organizar, empujar, colaborar, inducir, proyectar...; algo que percibían inmediatamente los docentes e investigadores más jóvenes pero también sus colegas más experimentados; una virtud, en fin, que le permitía ejercer sobre el colectivo la intensa y natural influencia de un maestro.

Aunque particularmente nada pueda añadir a estos rasgos de Julio, sí que puedo testificar de manera directa su saber hacer en la tarea de "armar" institucionalmente el campo de la historia de la educación a partir de la experiencia que compartimos durante su paso por la universidad de Oviedo, en la que yo trabajaba cuando él llegó como catedrático en el año 1983. Una experiencia que, por otra parte, es hija de una época -hablo de la década de ochenta- en la que la universidad española transformó completamente sus antiguas estructuras organizativas, de docencia e investigación, poniendo en pie un "edificio modernizado" cuyas luces y sombras no es ahora el momento de valorar. El desgajamiento y diversificación de las antiguas facultades, la nueva definición de los Departamentos como integradores de las denominadas desde entonces "áreas de conocimiento", la puesta en pie, prácticamente ex novo, de estructuras específicas destinadas a la investigación (administrativas, organizativas, financieras), las nuevas categorías de profesorado y un sinfín más de transformaciones fueron el marco en el que se produjo ese encuentro.

La llegada de Julio a Oviedo como catedrático de Historia de la Educación fue para mí una auténtica sorpresa. De hecho lo encontré un día en que yo salí de clase (llevaba unos seis años como profesora no numeraria de Historia de la Educación de la entonces 
Facultad de Filosofía, Psicología y Ciencias de la Educación) y me encontré de sopetón con mi antiguo profesor de la Complutense. Ese desconocimiento por mi parte de que había una cátedra de la universidad de Oviedo en oposición y de que Ruiz Berrio había sido nombrado para la misma puede parecer hoy alucinante. Pero así eran entonces las cosas en una pequeña universidad de provincias, en cuya facultad de educación Gustavo Bueno era entonces (salvo que me falle la memoria) el único catedrático. 0 lo eran, al menos, para los PNNs que en aquellos años estábamos peleando desde las Coordinadoras por el contrato laboral, así como por una universidad pública, democrática y abierta a las necesidades sociales y una investigación al servicio de las mismas.

Por entonces yo reunía a mis alumnos y alumnas mas interesados en ello en un autodenominado "Seminario de Historia de la Educación de Asturias". Eran los años en que muchos maestros y maestras en ejercicio, comprometidos y empeñados en la mejora de la escuela, llenaban un "Curso Puente" que constituía una delicia para nosotros, sus profesores: explicar, por ejemplo, lo que supuso en 1901 para el magisterio el paso a la condición de funcionarios; explicárselo, digo, al alumnado del "Grupo A" (estudiantes de licenciatura procedentes del bachillerato) o al "Grupo B" (curso puente) eran dos experiencias docentes completamente diferentes: nos alimentábamos del curso puente. $Y$ por eso extendíamos nuestra acción conjunta en el "Seminario", en el que planificábamos trabajos de localización de fuentes en sus propias localidades y escuelas, elaborábamos provisionales historias escolares, realizábamos entrevistas a antiguos maestros y procedíamos a la recuperación de materiales. Pensar en aquella experiencia, que era, por otra parte, relativamente frecuente entre el profesorado joven de aquel tiempo, me produce todavía hoy (y sé que también a muchos de aquellos alumnos) un magnifico sabor de boca.

¿Que aportó Julio a esta dinámica? De manera resumida diría que dio forma institucional a la misma. Conquistó al alumnado, entusiasmándolo para "conformar" lo que estábamos haciendo: realizó las oportunas gestiones para que el Seminario quedase oficialmente denominado e integrado en una, también inscrita y registrada, "Sección de Oviedo del Centro de Educación Comparada" -Sección que, por acuerdo colectivo pero gracias a su empeño, presentó los correspondientes proyectos de investigación al recién creado Vicerrectorado de Investigación-; sistematizó sus reuniones aportando fuentes, bibliografía, lecturas, etc...; y su actividad incansable y entusiasta siguió entusiasmando y atrayendo a más alumnos cuando el desarrollo de algunos de esos proyectos de investigación exigieron la formación de grupos que temporalmente debían desplazarse a Madrid para consultar la Biblioteca Nacional o los fondos del Instituto San José de Calasanz; ello, junto con la elaboración de alguna pequeña y local publicación fruto de estos trabajos, supuso para el alumnado participante una experiencia inolvidable e impensable en la dinámica de esa universidad de provincias en que nos movíamos. El futuro profesional de algunos de aquellos alumnos y alumnas ligado a la historia de la educación se decidió, sin duda, entonces.

Como sabemos todos sus colegas, una tarea a la que se entregaba Julio con entusiasmo era la organización de Seminarios, Jornadas, Congresos, Encuentros... Y 
también en esto fuimos iniciados ya entonces. Con esos mismos alumnos a los que me refiero (aquellos que, año tras año, era capaz de entusiasmar para estas actividades de "Seminario") recuerdo la que quizá fuera la primera de las actividades de este tipo en la que nos "embarcó". Se denominó Encuentro cultural en Castropol. Y una vez más fue para los alumnos y los profesores que participamos una experiencia que me atrevería a llamar institucionista. El lugar, Castropol, en la costa asturiana casi frontera con Galicia, es una hermosa villa marinera con un magnífico Casino en un edificio probablemente indiano. Y el motivo, la conmemoración de no se qué aniversario de las Misiones Pedagógicas. Los actos, conferencias de él mismo y algunos colegas quizá de Galicia (sigo hablando de memoria y no quisiera caer en la debilidad profesional de documentarme) y otros de los que estábamos haciendo nuestras tesis bajo su dirección. Visitas a pueblos y escuelas del contorno en los que había habido actividades de las Misiones Pedagógicas durante la República. Alojamiento en un hermoso hostal sobre la ría, algunos baños (era junio) y, especialmente memorable, un concierto de piano que Julio se empeñó en que formara parte de los actos, aunque ello supusiera llevar un piano alquilado desde Oviedo. Estoy segura de que en Castropol se guardó durante tiempo memoria de aquellos actos. Nosotros la hemos guardado.

No quiero ni debo extenderme más. Estos son, quizá, los mejores y más nítidos recuerdos que guardo de Julio en Oviedo. El siguió dando forma a la dinámica universitaria de la época: fue director del Departamento de Ciencias de la Educación desde su creación, dirigió numerosas tesis doctorales de profesores de nuestra Facultad y de la entonces Escuela de magisterio, amplió las dotaciones de nuestra minúscula biblioteca con libros y, sobre todo, revistas nacionales e internacionales, contribuyó a la promoción de los profesores de su campo de conocimiento (y sin duda también de otros), fue miembro activo del Claustro universitario cuando se estaban definiendo sus nuevos Estatutos...; lo hizo mientras vivía a mucha distancia física de su familia (a la que religiosamente visitaba cada fin de semana) y en un tiempo en que su salud sufrió quebrantos importantes. Durante todos esos años compartimos literatura, lecturas profesionales, noticias de prensa, comentarios sobre la evolución política, sobre las diatribas de los tertulianos, cotilleos de no muy baja estofa, acuerdos (sobre todo de tipo intelectual) y las discrepancias propias de una profesora novel, representante sindical y relativamente irreverente con los aspectos formales (sin riesgos excesivos) con alguien que los tenía incrustados en su propia concepción del mundo y de quien aprendí a darles el enorme valor que tienen. Me he referido en otro momento a la capacidad de trabajo de Julio, a su sistematicidad en el mismo. Esa es también otra lección que le debo. 